Revue d'histoire du XIXe siècle

Société d'histoire de la révolution de 1848 et des

révolutions du XIXe siècle

$28 \mid 2004$

Religion, politique et culture au XIXe siècle

\title{
Protestantisme et bonapartisme
}

\section{Andre Encrevé}

URL : http://journals.openedition.org/rh19/622

DOI : $10.4000 /$ rh19.622

ISSN : $1777-5329$

Éditeur

La Société de 1848

Édition imprimée

Date de publication : 1 juin 2004

Pagination : 111-131

ISSN : 1265-1354

Référence électronique

Andre Encrevé, "Protestantisme et bonapartisme », Revue d'histoire du XIXe siècle [En ligne], 28 | 2004 , mis en ligne le 07 avril 2008, consulté le 19 avril 2019. URL : http://journals.openedition.org/rh19/622 ; DOI : 10.4000/rh19.622

Ce document a été généré automatiquement le 19 avril 2019

Tous droits réservés 


\title{
Protestantisme et bonapartisme
}

\author{
Andre Encrevé
}

1 «L'homme [Napoléon III] est prisonnier, et son trône s'est écroulé en poussière. [...] Le Tout-Puissant a dévoilé son bras, et renversé en un instant cet édifice de scélératesse et d'infamie qu'on voulait rendre immortel. [...] Les succès persévérants de ce bandit ont été, pendant de longues années et tout récemment encore, une insulte à la conscience humaine et à la justice divine. Il y aura dix-neuf ans bientôt que, dans une nuit d'exécrable mémoire, lui, le seul magistrat de la République qui eût prêté serment à la Constitution, foula aux pieds toutes les lois, et fit jeter en prison, à l'exil, ou dans la tombe les défenseurs de la liberté, tous ceux qui formaient le rempart et l'honneur de la patrie. [...] Quant au naufrage même de ce qu'on appelait l'empire, et à la chute du tyran, nous n'avons, pour le moment, qu'un cri : Peuples prosternez-vous, et laissez passer la justice de Dieu ! » écrit le pasteur Ch. Luigi dans le premier numéro de L'Église libre paru après le 4 septembre $1870^{1}$. Et, pour faire bonne mesure, il ajoute que les désastres militaires que connaît alors notre pays sont un châtiment provoqué par le péché que vient de commettre la France en donnant une forte majorité au oui lors du plébiscite du 8 mai $1870^{2}$.

2 Le protestantisme serait-il incompatible avec bonapartisme? Pourtant, sous le Premier Empire, les réactions des protestants sont bien différentes. Ainsi, par exemple, le 5 avril 1808 le pasteur Martin, président du consistoire de l'Église réformée de Bordeaux, s'adresse à Napoléon $\mathrm{I}^{\mathrm{er}}$ en ces termes : "Sire, tandis que l'univers vous contemple, que l'Europe vous admire, et que la France vous proclame son libérateur, les protestants vous chérissent comme leur père... Avec quelle assurance ne pouvez-vous pas compter sur des sujets qui vous doivent tout ; [...] quand vos bienfaits envers nous sont sans nombre, n'estil pas juste que notre reconnaissance soit sans bornes? [...] Sire, satisfaits d'avoir admiré sur le trône la sagesse de Socrate, le courage d'Alexandre, le génie de César, la clémence d'Auguste, le zèle de Constantin, la bonté d'Henri IV... eh ! que dirons-nous encore ? Tous les talents, toutes les vertus et toutes les gloires réunies en votre personne sacrée, nous allons retourner dans nos églises, et raconter ce que nous avons vu, ce que nous avons oui... Que de merveilles n'aurons-nous pas à décrire ! ${ }^{3}$ 
Certes, ces deux textes ne traitent pas du même empereur. Il reste qu'au début du XIX siècle la plupart des protestants ne semblent pas regarder le régime de Napoléon $\mathrm{I}^{\mathrm{er}}$ comme contraire à leurs principes religieux, tandis qu'à la fin des années 1860, nombre de pasteurs et de fidèles jugent le bonapartisme pratiqué par son neveu comme incompatible avec leur vision de la vie politique et sociale. Toutefois, cela ne se produit que progressivement et cette opinion n'est pas partagée par l'ensemble de la communauté protestante (mais a-t-on jamais vu des protestants unanimes ?). Par ailleurs, cela illustre aussi la complexité du bonapartisme, qui varie dans le temps et qui n'est pas perçu de la même façon dans toutes les régions de France.

Avant de commencer l'analyse il convient donc de se demander si l'on peut trouver des antagonismes de principe entre le protestantisme et le bonapartisme.

Qu'est-ce qu'un protestant? Les trois bases fondamentales sont connues: sola scriptura (seule l'Ecriture est règle de foi), sola fide (seule la foi est salvatrice) et sacerdoce universel. En ce qui concerne les choix politiques et sociaux, ce dernier point est important. Pour les protestants il n'y a qu'une différence de fonction entre les laïcs et les pasteurs. Contrairement à ce qui est de règle dans l'Église catholique, ces derniers, ne disposent pas du monopole de l'interprétation de la Bible : les laïcs sont invités à lire la Bible et à la méditer sans intermédiaire (" Tout protestant est pape une Bible à la main » écrivit Boileau). Au fond, il me semble qu'on peut définir un protestant comme un être humain qui refuse d'admettre ce que sa conscience tient pour contraire à la Parole de Dieu telle qu'il la trouve dans la Bible, ce qui induit une primauté de la conscience individuelle sur l'autorité, tant ecclésiastique que politique. Et l'invitation faite à chaque fidèle de se forger lui-même ses convictions, « devrait ", en théorie, écarter a priori les protestants de toute sympathie pour les gouvernements autoritaires ${ }^{4}$. D'ailleurs, chacun sait que la démocratie représentative moderne est née dans le monde anglo-saxon, et donc dans la sphère intellectuelle et sociale influencée par le protestantisme.

Ces remarques s'appliquent à tous les protestants. Dans le cas français, les vicissitudes de l'histoire ont imprimé leur marque aux réactions des « huguenots ». On sait qu'après 1685 l'État et l'Église romaine ont utilisé tous les moyens, même les plus violents, pour tenter de faire disparaitre le protestantisme du royaume de France et que ces persécutions ont duré un siècle. Naturellement, au début du XIX siècle, et encore dans les années 1850 et 1860 , le temps des persécutions n'est pas oublié dans les rangs des huguenots. Cela induit, évidemment, un très fort attachement aux principes de 1789. En effet, outre qu'ils ne voient aucune incompatibilité entre la philosophie de Lumières et la doctrine chrétienne (bon nombre des penseurs des Lumières sont protestants), les protestants savent qu'il a fallu le renversement d'un Ancien Régime fondé sur l'union intime de la monarchie et de l'Église catholique pour qu'ils obtiennent la liberté et l'égalité. L'attachement aux principes de 1789 et à l'œuvre de la Révolution (elle les réintègre au sein de la communauté nationale) est donc très fort dans leurs rangs, ce qui, dans la configuration de la vie politique française jusqu'en 1914, en fait généralement des hommes de gauche. D'autre part cela induit chez eux une très grande méfiance, pour ne pas dire plus, à l'encontre de l'Église romaine et de ses alliés ${ }^{5}$, d'autant qu'au XIX siècle l'Église catholique est officiellement hostile à la liberté religieuse ${ }^{6}$. Mais aussi une profonde méfiance à l'encontre de l'État, qui les a persécutés durant plus d'un siècle. Depuis 1789, il est vrai, ils n'ont plus affaire à l'État monarchique, mais cela ne les empêche pas de rester vigilants et de refuser toute confiance a priori au détenteur du pouvoir. En revanche les principes protestants n'induisent pas, de façon théorique, un refus de la monarchie et une 
préférence pour la République, du moment que la monarchie accepte toutes les conséquences du sacerdoce universel ${ }^{7}$. Ce sont les particularités de la vie politique française qui conduisent la plupart des protestants français à se montrer de très fermes républicains après 1870 .

Les principes protestants s'opposent-ils au bonapartisme ${ }^{8}$ ? Certes ni Napoléon $\mathrm{I}^{\mathrm{er}}$ ni son neveu n'ont véritablement théorisé leur régime. Il est toutefois possible de dégager un certain nombre de points. Tout d'abord, il est clair que le bonapartisme est issu de 1789 . La Constitution de 1852 indique d'ailleurs dans son article premier: «La Constitution reconnait, confirme et garantit les grands principes proclamés en 1789, et qui sont la base du droit public des Français ». Cependant, le bonapartisme se définit aussi comme un régime autoritaire. "Il existe - écrit Jacques-Olivier Boudon - [...] une certaine similitude chez Napoléon entre la conduite des affaires militaires et la gestion des questions politiques. Il n'entrevoit que la réussite de ses projets et culbute de la même façon l'opposition, qu'elle brandisse des armes ou des mots " ${ }^{9}$. D'ailleurs, le timide essai de parlementarisme esquissé en 1800-1802 tourne vite à la caricature, même si Napoléon I er conserve certaines formes constitutionnelles, vidées de leur sens. En ce domaine Napoléon III n'est pas moins autoritaire et, selon René Rémond, dans les années 1850 l'Empire est un « régime de droit et de fait pour lequel le terme de dictature n'est pas excessif ${ }^{10}$. Il est aussi profondément antiparlementaire. Certes, le Second Empire, comme le Premier, comporte in fine une phase partiellement libérale, mais, dans les deux cas, celle-ci est trop brève pour marquer ces régimes. Il reste qu'en principe le bonapartisme est tout de même fondé sur le suffrage universel, ce qui rappelle aussi que l'égalité devant la loi, acquis fondamental de 1789, est préservée par le bonapartisme.

8 En ce qui concerne la question religieuse, Bonaparte signe certes un Concordat avec le pape, ce qui rend à l'Église romaine une place officielle dans l'État; mais il s'agit surtout d'une mesure de pacification religieuse, qui ne rétablit nullement l'Église catholique dans le statut qui était le sien avant 1789. Le catholicisme n'est plus la religion de l'État, mais seulement celle de « la majorité des citoyens français », ce qui est une simple constatation de fait et, surtout, les Églises protestantes (puis la communauté juive) sont reconnues au même titre que l'Église catholique et l'on promet aux non catholiques l'égalité civile et religieuse. Et l'on ne peut pas dire que Napoléon $I^{\text {er }}$, qui se brouille rapidement avec le pape, mène une politique cléricale. Il en est tout autrement de son neveu; dans les années 1850 on constate une véritable union du trône et de l'autel et, en dépit des difficultés provoquées par la politique italienne de Napoléon III, le Second Empire conserve dans les années 1860 une tonalité cléricale, renforcée en 1870 avec l'Empire « libéral».

9 Pour le reste, Napoléon $\mathrm{I}^{\mathrm{er}}$, peu théoricien, s'attache à réaliser de vastes réformes (financières, judiciaires, scolaires, etc.), qui marquent durablement la société française, mais ne permettent pas de distinguer une véritable idéologie «bonapartiste ». Le Second Empire apporte une touche plus originale puisqu'il assigne aussi à l'action politique un objectif de développement économique et de progrès social, tout en restant dans le cadre du système de l'économie libérale. Par ailleurs, à l'extérieur, dans la droite ligne des principes de 1789, il défend le principe des nationalités, contre le droit des princes, ce qui est en. Au fond, on peut dire que le bonapartisme de Napoléon III emprunte des éléments à la gauche (principes de 1789, volonté de favoriser le progrès économique, lois sociales, défense des nationalités) et d'autres à la droite (refus du respect des grandes libertés 
publiques, cléricalisme, autoritarisme, défense de l'ordre et de la propriété), d'où la difficulté à le classer et les réactions différentes qu'il peut entraîner ${ }^{11}$.

Ces éléments induisent-ils une réaction protestante spécifique? Il convient de distinguer les deux Empires successifs, mais aussi, pour chacun d'eux, l'attitude des élites sociales et celle du peuple protestant ${ }^{12}$.

11 Pour le Premier Empire, en ce qui concerne les élites, on peut noter la présence de quatre banques protestantes dans la société dite des «Vingt négociants réunis » qui, en frimaire an VIII, avance douze millions au nouveau gouvernement dirigé par Bonaparte : au moins une partie de la «banque protestante » fait confiance au nouveau régime ${ }^{13}$. Il reste qu'on ne remarque pas de protestants parmi les ministres et les proches collaborateurs de Napoléon. Otto de Mosloy fait exception, mais, allemand d'origine il n'est pas représentatif du protestantisme français; certes, il est nommé ministre d'État en 1813, mais il s'agit seulement d'un titre honorifique ${ }^{14}$. En fait, cette faible présence protestante dans les allées du pouvoir ne doit probablement pas être comprise comme un signe de défiance des élites sociales protestantes à l'encontre de Bonaparte, ou de ce dernier à l'encontre des protestants. Outre qu'il y a une part de contingence dans le choix d'un ministre, cela doit plutôt être interprété, à notre sens, comme la conséquence d'un siècle de persécutions monarchiques. Certes le protestant Jacques Necker est ministre des Finances de 1777 à 1781, et même principal ministre entre août 1788 et juillet 1789, mais il est étranger (suisse) ce qui permet au roi de recourir à ses services sans déroger à la législation persécutrice du royaume. Et, d'une façon générale, on doit surtout noter que, l'Alsace mise à part, entre 1685 et 1789 les protestants français sont exclus de tous les établissements d'enseignement ${ }^{15}$ ainsi que de la fonction publique, ce qui ne les prépare pas à participer au gouvernement de la France, et explique probablement leur absence au sommet de l'État entre 1799 et $1815^{16}$. D'autant plus que l'absence de toute hostilité de la part de Napoléon I ${ }^{\mathrm{er}}$ a l'encontre du protestantisme a souvent été notée ; et qu'il a même fait à plusieurs reprises des déclarations favorables au protestantisme, probablement par politesse il est vrai ${ }^{17}$.

Par ailleurs, des protestants sont associés au pouvoir sous le Consulat et l'Empire, par le biais de leur participation aux assemblées politiques. On remarque ainsi dix protestants sur les 114 membres qu'a compté le Tribunat, soit $9 \%$ (alors que la communauté protestante rassemble environ $2 \%$ des Français) ${ }^{18}$; dont Benjamin Constant, JeanBaptiste Say, François Antoine Boissy d'Anglas et François-Arnail de Jaucourt. Entre l'an X et 1814 on dénombre aussi 20 protestants membres du Corps législatif, qui possède 300 membres renouvelables chaque année par cinquième ; parmi eux Pierre-Antoine RabautDupui (dit aussi Rabaut le jeune), dernier fils du pasteur Paul Rabaut, connu pour avoir adhéré avec éclat à la Constitution de l'an VIII, en la qualifiant de « pacte conservateur des principes sur lesquels fut constituée notre immortelle Révolution ». Quant au Sénat (80 membres) on n'y compte que cinq protestants français, dont seulement trois nés en France (Boissy d'Anglas, Jaucourt et Sers) ${ }^{19}$. Mais on sait que pour être sénateur, il faut avoir au moins 40 ans ; et le Sénat étant au sommet de la hiérarchie des notabilités, il est nécessaire de s'être illustré avant d'y être nommé. Or les difficultés de formation et d'accession aux grands emplois pour les protestants français avant 1789 expliquent sans doute ce nombre relativement faible de protestants (nés en France) au Sénat. De 1799 à 1815 on dénombre aussi un nombre non négligeable de protestants parmi les hauts fonctionnaires: huit conseillers d'État, neuf préfets, trois ambassadeurs, 28 généraux nommés entre 1799 et 1815 (dont Jean Rapp, qui fut aide de camp du Premier Consul) ${ }^{20}$, 
un vice-amiral (Verhuell, d'origine hollandaise), un professeur à la Sorbonne (Guizot) ${ }^{21}$ etc.

Que retenir de cette énumération? Il est clair que les élites de la communauté protestante française, qui n'ont aucune raison de regretter si peu que ce soit l'Ancien Régime, ne voient en général aucune incompatibilité entre leurs choix religieux et la participation à un pouvoir politique bonapartiste. Sans doute apprécient-ils d'être associés à la direction de l'État au même titre que les catholiques, d'autant plus que la plupart d'entre eux ont vécu le temps des persécutions. Après la réintégration des huguenots au sein de la communauté nationale édictée par la Révolution sur le plan des principes, ils expérimentent ainsi par eux-mêmes la réalité de l'égalité civile. Cela leur est d'autant plus facile à accepter que, pour la première fois dans l'histoire de France, l'État (dirigé par Bonaparte) a reconnu officiellement les cultes protestants en 1802 et qu'il s'efforce de mettre en application non seulement la liberté mais aussi l'égalité des cultes, et que les pasteurs, accoutumés avant 1787 à se cacher pour ne pas être mis à mort, sont désormais des personnages officiels, rétribués par l'État et invités, en tant que tels, aux cérémonies officielles.

Toutefois, cette orientation politique générale du Consulat et de l'Empire ne peut dissimuler que l'essence même du bonapartisme est autoritaire, tandis que l'essence du protestantisme ne l'est pas, bien au contraire. Il n'est donc pas surprenant que, parmi les élites protestantes, la fraction la plus en vue, mais aussi la plus idéologique, se soit assez vite retrouvée dans l'opposition. Tel est le cas des deux intellectuels protestants les plus notables de ce temps, Germaine de Staël et Benjamin Constant, et c'est bien sûr le problème de la liberté, et donc de l'incompatibilité entre le libéralisme et l'exercice bonapartiste du pouvoir, que se fait la rupture. De fait, tant Mme de Staël que Benjamin Constant - l'un et l'autre de formation suisse - exaltent les liberté anglaises (mais aussi protestantes), pour les opposer à l'absence de liberté qui règne dans la France de Napoléon, tandis que Coppet, où Germaine de Staël qui a rompu avec Napoléon dès 1803 est pratiquement assignée à résidence, fait figure de capitale du libéralisme, puisque la fille de Necker y reçoit l'intelligentsia européenne indépendante de Napoléon. Certes, ce couple célèbre accepte dans un premier temps le coup d'État du 18 brumaire et Mme de Staël réussit à faire entrer Benjamin Constant au Tribunat grâce à l'aide de Joseph et de Lucien Bonaparte. Mais quatre jours après l'ouverture de la première session de ce corps, un discours de Constant montre bien tout ce qui sépare le libéralisme qui l'anime du projet politique de Bonaparte, puisqu'il y défend l'indépendance du Tribunat dans le processus de formation de la loi, déclarant notamment: "Sans l'indépendance du Tribunat, il n'y aurait plus ni harmonie ni constitution, il n'y aurait que servitude et silence ; silence que l'Europe entière entendrait et jugerait " ${ }^{22}$. Bonaparte s'étant écrié à propos de ce discours " c'est une honte ", il n'est pas surprenant que Benjamin Constant ait été éliminé du Tribunat dès le premier renouvellement, en 1802, d'autant plus qu'il avait eu l'audace de voter contre les tribunaux spéciaux. D'ailleurs, en 1814, Constant accueille fort bien les Bourbons et, le 15 mars 1815, il écrit un article violemment hostile au retour de l'̂lle d'Elbe, où l'on peut lire : « Napoléon [...] c'est Attila, c'est Gengis Khan [... ]. J'ai voulu la liberté sous diverses formes; j'ai vu qu'elle était possible sous la monarchie; j'ai vu le roi se rallier à la nation. Je n'irai pas, misérable transfuge, me traîner d'un pouvoir à l'autre, couvrir l'infamie par le sophisme et balbutier des mots profanés pour racheter une vie honteuse ${ }^{23}$. Certes, le 14 avril il accepte de se rallier à l'Empereur ${ }^{24}$; mais c'est au titre de principal porte-parole des libéraux et la nouvelle 
constitution qu'il contribue très largement à rédiger ${ }^{25}$ ne renie pas, bien au contraire, les principes du libéralisme. D'ailleurs, réfléchissant sur le sens de son action, il écrit en 1829 : «J'ai défendu quarante ans le même principe : liberté en tout, en religion ${ }^{26}$, en philosophie, en littérature, en industrie, en politique ; et par liberté j'entends le triomphe de l'individualité tant sur l'autorité qui voudrait gouverner par le despotisme que sur les masses qui réclament le droit d'asservir la minorité à la majorité. Le despotisme n'a aucun droit » ${ }^{27}$. Phrases qu'il n'est pas surprenant de trouver sous la plume d'un descendant de « réfugiés » huguenots ${ }^{28}$.

D'ailleurs, Constant n'est pas le seul notable protestant à prendre rapidement ses distances avec la pratique bonapartiste du pouvoir. Jean-Baptiste Say, théoricien du libéralisme économique, lui aussi issu d'une famille passée par le « refuge », écrit à propos de son appartenance au Tribunat: «Je m'aperçus bien vite qu'on voulait non pas travailler de bonne foi à la pacification de l'Europe et au bonheur de la France, mais à un agrandissement personnel et vain ${ }^{29}$. Et, comme il vote contre l'établissement de l'Empire, il est éliminé du Tribunat dès l'an XII. Quant à Guizot, théoricien du libéralisme politique, il prend parti pour les Bourbons en 1814, et fait même le voyage à Gand au moment des Cent-Jours. Il écrit au début de ses Mémoires: «Je ne suis entré qu'en 1814 dans la vie publique [...]. Étranger par mon âge à la Révolution, je suis resté étranger à l'Empire par mes idées». Il ajoute: «En rendant hommage à sa grandeur [celle de Napoléon], je ne regrette pas de ne l'avoir apprécié que tard, quand il n'était plus; il y avait pour moi, sous l'Empire, trop d'arrogance dans la force et trop de dédain du droit, trop de révolution et trop peu de liberté $»^{30}$.

$\mathrm{Au}$ fond, ces diverses citations montrent bien que les penseurs protestants sont réticents devant la pratique politique de Napoléon I ${ }^{\mathrm{er}}$, en particulier son refus du libéralisme politique et du parlementarisme. Et la participation des élites protestantes aux affaires publiques dans les premières années du régime ne peut passer pour un ralliement idéologique, leurs préférences allant nettement vers un pouvoir inspiré de l'exemple britannique, protestant de surcroît.

Pour le peuple protestant les choses sont un peu différentes. On peut, ainsi, citer d'assez nombreuses adresses, de pasteurs ou de consistoires, particulièrement élogieuses envers le pouvoir à l'occasion de divers événements. Nous avons signalé, en introduction, la harangue du pasteur Martin, de Bordeaux. On peut en évoquer d'autres, comme, par exemple le sermon prononcé dans le temple de Lyon le 15 août 1809 "à l'occasion de la fête de S. M. impériale et royale Napoléon le Grand", où l'on peut lire, notamment: "Qu'il est doux pour les bons citoyens de voir les destinées de la patrie confiées à un Prince que le ciel semble avoir formé pour effacer la gloire des souverains qui vécurent avant lui, et pour offrir aux âges suivants le tableau d'un grand souverain. [...] Quelle perfection n'atteindrait pas le genre humain, si chacun s'acquittait, avec une ardeur semblable à la sienne, des obligations de son état " ${ }^{31}$. À l'occasion de la promulgation des Articles organiques des cultes protestants, on remarque aussi toute une série d'adresses particulièrement élogieuse, rédigées par des porte-parole de groupes protestants. Mais, outre qu'il s'agit là d'une simple éloquence officielle alors courante, ces adresses ont été sollicitées ${ }^{32}$. De plus, rien n'interdit de penser que, en dépit des problèmes que leur posent les Articles organiques ${ }^{33}$, la plupart des protestants français aient fait preuve, dans un premier temps, d'une satisfaction raisonnée de voir leurs Églises reconnues officiellement, tandis que le pouvoir leur promettait l'égalité civile et religieuse. En effet, affaiblie par un siècle de persécutions et par une dizaine d'années de secousses 
révolutionnaires, au moment du coup d'État du 18 brumaire, les communautés protestantes sont prêtes à accepter n'importe quel régime, pour peu qu'il n'impose rien de contraire à leur foi et à leur conscience. On peut, d'ailleurs, trouver une expression de cette satisfaction limitée en face du Premier Empire dans l'introduction, intitulée «Aux chrétiens réformés de l'Empire français » que publie Rabaut-Dupui en 1807 en tête de l' Annuaire qu'il fait paraitre. On y lit notamment : "Louis XIV ne voulut qu'une Religion dans ses états, et proscrivit tous ceux qui ne furent pas de la sienne : le grand Napoléon les appelle toutes; il promet à toutes la liberté. L'empire de la loi, dit-il, finit où commence l'empire indéfini de la conscience; ni la loi, ni les princes ne peuvent rien contre cette liberté. La nation juive elle-même, depuis tant de siècle proscrite et dispersée va recevoir une existence civile, politique et religieuse [...]. Vous qui vécûtes comme nous sous le joug de l'intolérance, résidu de tant de générations persécutées, voyez et comparez : ce n'est plus dans les déserts et au péril de votre vie que vous rendez au créateur l'hommage qui lui est dû [...]. Nous sommes appelés comme les autres citoyens aux fonctions publiques; nos propriétés sont protégées; nous pouvons avec sécurité transmettre nos héritages à nos enfants et chacun de nous peut cultiver en paix sa vigne et son figuier ${ }^{34}$.

Cela ne fait pas des protestants ni des bonapartistes idéologiques ni de véritables partisans du gouvernement de Napoléon. Ils sont heureux de la stabilisation politique et du maintien des principaux acquis religieux et sociaux de la Révolution, mais cela ne semble pas aller au-delà. Évidemment, en l'absence de toute presse libre et de toute élection digne de ce nom, il n'est pas facile de savoir exactement ce que pense la grande majorité des fidèles. Toutefois, comme l'a bien montré Daniel Robert, les protestants ne font jamais preuve d'enthousiasme envers le régime ou la personne de son chef. Ils montrent une simple "joie raisonnée et limitée " ${ }^{35}$ au moment de la promulgation des Articles organiques. Leur manque d'enthousiasme s'explique par le refus persistant de Napoléon de laisser des synodes protestants se réunir, alors que ceux-ci sont au cœur même de l'identité des réformés. Ce ne sont donc pas seulement les théoriciens protestants du libéralisme politique qui s'opposent à l'autoritarisme bonapartiste ; même les pasteurs de campagne et les paysans des Cévennes ou du Poitou peuvent mesurer, à l'usage, que l'essence autoritaire du bonapartisme est en contradiction avec l'ecclésiologie protestante. Toutefois, en dépit de ce manque d'enthousiasme, tant que Napoléon continue à faire preuve d'impartialité et à respecter la liberté religieuse et l'égalité civile, ce qui est le cas jusqu'à sa chute, les protestants n'ont pas de raison de se conduire en opposants. Ils évoluent, semble-t-il, comme les autres Français : à partir des années 1809-1810 ils se lassent des guerres continuelles et en 1814 la chute de Napoléon et le retour des Bourbons ne suscite dans les rangs des protestants aucune crainte spécifique. D'ailleurs, en 1814, Jaucourt est l'un des cinq ministres du gouvernement provisoire nommé par le Sénat après la capitulation de Paris, alors que deux protestants (Boissy d'Anglas et Chabaud-Latour) sont membres de la commission chargée de préparer la Charte de 1814.

$19 \mathrm{Au}$ fond, l'attitude des protestants lors du Consulat et de l'Empire montre bien que l'autoritarisme consubstantiel au bonapartisme ne fait pas bon ménage avec les conséquences ecclésiologiques et politiques que les protestants français tirent, au début du XIX siècle, de la doctrine du sacerdoce universel. Mais, hormis quelques théoriciens du libéralisme, les huguenots ne deviennent pas des opposants, d'autant que le bonapartisme est clairement issu des principes de 1789, chers au cœur des huguenots. 
Tout est donc affaire de nuance et la pratique du pouvoir compte beaucoup dans l'attitude, rationnelle, que les protestants adoptent jusqu'en 1815 .

Le Second Empire, nouvelle incarnation du bonapartisme, permet d'affiner l'analyse des rapports entre protestantisme français et bonapartisme. Cependant, il convient de se souvenir des événements des années 1815-1848. Tout d'abord, durant l'été 1815 dans le Gard, les protestants subissent la Terreur blanche : durant plusieurs mois, de mi-juillet à fin novembre, ils sont victimes d'agressions, d'extorsions de fonds, d'incendies (de temples ou de propriétés), de violences diverses, de meurtres (sans doute plus d'une centaine), etc. Or ils sont aussi agressés comme bonapartistes (les attaques sont politicoreligieuses), ce qui peut paraître surprenant ; mais le terme est alors plutôt synonyme de partisans de la Révolution puisque, sous la Restauration et jusqu'aux années 1840 (au moins) il y a une certaine interpénétration du républicanisme et du bonapartisme. Cet épisode a des conséquences politiques: désormais il y a du sang entre la dynastie des Bourbons et les protestants et ce sang a coulé lorsque l'Église romaine était l'alliée du pouvoir. Pour la plupart des protestants, la rupture, improbable en 1814, est devenue définitive ${ }^{36}$ et les quelques protestants légitimistes se verront toujours jeter au visage l'accusation de complicité avec les assassins de leurs frères, tandis que la crainte de l'union de trône et de l'autel est fortement ravivée. Mais cela conduit-il les protestants vers la République? Ce choix n'est pas immédiat, d'autant plus que longtemps, pour une fraction de l'opinion tout au moins, la République rappelle trop 1794, la guillotine et l'absence de liberté. On comprend pourquoi une bonne partie des élites protestantes a appuyé la Monarchie de Juillet. Ce régime, qui se réclame de 1789 (drapeau tricolore) tout en prenant modèle sur la monarchie britannique. De plus, la présence d'un premier ministre protestant (Guizot) et le mariage du prince héritier (le duc d'Orléans) avec une protestante ne peut que renforcer les sympathies de la bourgeoisie protestante. Il est cependant malaisé de connaître les préférences politiques du peuple protestant. Toutefois, comme il accepte fort bien la République en 1848, on peut penser que son « orléanisme » est limité et qu'il voit surtout dans la Monarchie de Juillet un régime libéral, non clérical et plutôt en froid avec la hiérarchie de l'Église romaine, ce qui induit plus une sympathie qu'une adhésion profonde.

Il reste qu'en 1848 la République est fort bien accueillie par les protestants, d'autant qu'elle manifeste immédiatement son respect de la liberté et, tout particulièrement, de la liberté religieuse. Mais qu'en est-il de leurs réactions en face du bonapartisme renaissant en la personne de Louis-Napoléon ? Grâce à la mise en application du suffrage universel, il est possible mieux connaître les choix du peuple protestant, d'autant plus qu'en 1848 les élections se déroulent dans un véritable climat de liberté, qui tranche avec les scrutins qui auront lieu sous le Second Empire. Il convient donc de s'y attarder quelque peu. Toutefois, en 1848 les choses ne sont pas simples à analyser. Bonaparte se présente alors comme un républicain, respectueux des institutions ${ }^{37}$, il bénéficie surtout de la gloire de son oncle, il n'a pas de programme très précis (défense de l'ordre, de la famille, de la religion, de la propriété) et il l'emporte, écrit Maurice Agulhon, par suite d'un « mouvement d'opinion irrationnel [...] une légende accrochée à un nom " ${ }^{38}$. L'étude des résultats est complexe: dans certaines régions Bonaparte est le candidat du "parti de l'ordre ", voire celui des légitimistes; dans d'autres, il est celui du peuple qui se souvient qu'il a écrit L'extinction du paupérisme, qu'il est l'héritier de la Révolution de 1789, et qu'il exprime le rejet de la classe dirigeante traditionnelle et le refus de la tutelle du clergé. 

sens du vote en faveur de Louis-Napoléon Bonaparte, se montrent assez divisés. D'ailleurs la presse protestante elle-même ne prend guère position, se retranchant derrière son caractère religieux. Toutefois un hebdomadaire protestant parisien, Le Semeur, affirme nettement son opposition à Bonaparte et son soutien à Cavaignac ${ }^{39}$. De même, dans le département du Gard, où un tiers des habitants sont protestants, Le Courrier du Gard, journal politique qui passe, avec raison, pour l'organe de la bourgeoisie protestante locale, défend la candidature de Cavaignac. Au fond, on constate qu'assez logiquement la bourgeoisie protestante, qui soutenait la Monarchie de Juillet avant 1848, conserve son choix fondamental en faveur du libéralisme, ce qui ne peut que la rapprocher de la république libérale et modérée incarnée par Cavaignac, et l'éloigner de Bonaparte et du bonapartisme. Comme nous le verrons, cette réticence fondamentale se maintiendra jusqu'en 1870 dans les rangs de la bourgeoisie.

23 Pour le peuple protestant les choses sont moins simples, même si les résultats de l'élection du 10 décembre 1848 permettent de tirer des conclusions, puisqu'on distingue deux attitudes différentes selon les régions ${ }^{40}$. Dans les départements du Sud-Est où les protestants sont nombreux, et où leurs réactions sont analysables (Gard, Lozère, Ardèche et Drôme), on ne remarque pas de tendance générale dans leurs rangs. Ainsi, par exemple, dans le canton de Saint-André-de-Valborgne (Gard) la première section ${ }^{41}$, où $99 \%$ des habitants sont protestants, accorde 83,2 \% de ses voix à Bonaparte et 15,4 \% à Cavaignac ; mais la seconde section, qui compte également $99 \%$ de protestants ne donne plus que $14,3 \%$ de ses voix à Bonaparte et $84,7 \%$ à Cavaignac. Dans l'ensemble du canton, protestant à $92 \%$, on dénombre $62 \%$ des voix pour Bonaparte ; mais dans le canton voisin de Lassalle, qui regroupe $87,5 \%$ de protestants, on ne compte plus que $15,5 \%$ des voix en sa faveur. Cette variété se retrouve dans la plupart des cantons du Gard ${ }^{42}$; il est donc clair que les protestants hésitent sur la nature de la candidature de Bonaparte. Dans ce département, les protestants, fortement marqués par les violences et les meurtres de la Terreur blanche de 1815, ont clairement une attitude de défense confessionnelle: ils entendent voter pour le candidat qui leur garantira la liberté de culte, l'égalité civile et la simple protection de leur vie et de celle de leur famille. Dans ce contexte, il est clair que Cavaignac, républicain modéré, insoupçonnable en matière de liberté religieuse, qui a refusé de faire figurer des mesures cléricales dans son programme, est un choix tout à fait possible pour les huguenots. Mais Bonaparte, neveu de l'Empereur qui a signé les Articles organiques des cultes protestants reconnaissant officiellement les Églises protestantes et leur promettant l'égalité civile et religieuse, n'apparaît pas menaçant. D'ailleurs, les protestants n'ont pas oublié qu'en 1815 c'est comme "bonapartistes» qu'ils ont été agressés par les royalistes catholiques. Certes, le parti de l'ordre, le clergé en particulier, soutient souvent Bonaparte en 1848, puisque ce dernier a acceptée de faire des promesses aux cléricaux; mais cela n'apparaît pas clairement dans sa propagande électorale ${ }^{43}$. Aussi, selon que Bonaparte apparaît comme l'homme du parti de l'ordre, et donc des prêtres et des royalistes, ou comme le neveu de Napoléon $\mathrm{I}^{\text {er }}$, l'homme des principes de 1789 qui a consolidé l'œuvre de la révolution et, en particulier, l'égalité des cultes, les résultats sont opposés. D'où les hésitations des protestants, non seulement dans le Gard, mais aussi dans les autres départements du Sud-Est où les protestants sont nombreux. En Lozère par exemple, dans le canton de Barre-des-Cévennes ( $86 \%$ de protestants), Bonaparte obtient $58,7 \%$ des voix et seulement $42,5 \%$ dans celui de Saint-Germain-deCalberte ( $73,5 \%$ de protestants). Il en est de même en Ardèche ${ }^{44}$. Quant au département 
de la Drôme, les protestants ne s'y singularisent guère ; d'ailleurs, dans ce département la nette victoire de Bonaparte peut être interprétée, certes, comme celle du parti de l'ordre, mais aussi comme celle ces masses populaires qui secouent la tutelle des notables favorables à Cavaignac ${ }^{45}$. Par ailleurs, dans cette région les protestants n'ont pas subi de violences en $1815^{46}$.

Dans le Sud-Est, on le voit, sans pouvoir être qualifié de "bonapartiste idéologique ", le peuple protestant n'est pas toujours réticent en face de la candidature de Bonaparte, en raison de ses ambiguïtés il est vrai. Toutefois, dans les régions de l'Ouest où les protestants sont nombreux (Poitou et Charentes, notamment) une tendance différente se distingue. En effet, en général le peuple protestant vote pour Bonaparte. Ainsi, par exemple, dans l'arrondissement de Melle (Deux-Sèvres) où les protestants regroupent le tiers de la population, Bonaparte obtient $94,7 \%$ des voix, et « seulement » $82,3 \%$ des voix dans l'ensemble du département des Deux-Sèvres; dans le canton de Celles-sur-Belle, où l'on dénombre $76 \%$ de protestants, Bonaparte rassemble $96,6 \%$ des votants. En réalité dans l'Ouest et le Sud-Ouest de la France, où le parti républicain est très faible et très peu organisé, le bonapartisme préfigure assez largement le radicalisme d'après 1879. Il possède une connotation anticléricale et permet au peuple de secouer la tutelle des notables et celle du clergé. Il incarne donc une forme de démocratisation de la vie politique, qui convient fort bien aux paysans protestants, qui craignent avant tout l'alliance du château et du presbytère, surtout quand ils sont soutenus par le pouvoir politique. Les paysans de ces régions ne sont pas moins attachés à la doctrine du sacerdoce universel et aux souvenirs des "galériens pour la foi» et des martyrs du «Désert » que ceux du Sud-est de la France, mais, dans la configuration politique de la région Ouest, c'est en votant pour Bonaparte qu'ils pensent défendre le mieux leur liberté religieuse.

Au fond, dès 1848 commence à s'esquisser l'attitude qui sera celle des protestants en face du bonapartisme de Napoléon III. Nette réticence de la bourgeoisie qui redoute l'autoritarisme du pouvoir politique, pour les raisons théoriques exposées plus haut mais aussi parce qu'elle soupçonne toujours un gouvernement autoritaire d'être conduit, par la force des choses, à s'associer à l'autoritarisme religieux qu'est à ses yeux l'Église catholique. Or elle constate que si la hiérarchie de l'Église romaine n'a plus aucune intention de réclamer la persécution des protestants, elle n'est pas encore acquise à la liberté religieuse, mais seulement à la tolérance des communautés protestantes anciennes, pour peu qu'elles se fassent oublier et surtout qu'elles ne cherchent pas gagner de nouveaux adeptes ${ }^{47}$. Elle maintient donc son adhésion au libéralisme parlementaire, qui peut s'incarner dans une monarchie orléaniste ou dans une république modérée. Mais elle ne peut pas adhérer, véritablement, au bonapartisme de Napoléon III, ce césarisme plébiscitaire qui exerce une dictature au nom des masses et grâce à l'appui d'un suffrage universel contrôlé (candidature officielle). D'autant plus qu'il fait dès 1849 le choix du cléricalisme (expédition de Rome) et qu'il pratique dès le coup d'État l'union du trône et de l'autel. Certains de ses membres peuvent éventuellement faire un bout de chemin avec lui, en fonction des circonstances (la peur sociale ressentie en décembre 1851), mais, collectivement, elle ne peut être classée parmi les bonapartistes. Pour le peuple protestant, les choses sont moins simples : dans l'Ouest il est clair que le vote pour les candidats bonapartistes n'est pas conservateur mais qu'il permet au contraire de s'émanciper de la tutelle du château et du presbytère, d'autant plus qu'une partie de ces notables sont royalistes. Il est donc celui de la plus grande partie du peuple protestant; 
mais les protestants de l'Ouest ne sont pas des « partisans » du régime de Napoléon III, ils ne sont que ses "clients", qui votent pour lui à condition qu'il satisfasse leur besoin de liberté religieuse et de sécurité. S'ils ne sont pas satisfaits de leur "fournisseur», ils peuvent fort bien en changer, et passer du côté des républicains, pour peu que ces derniers sachent s'organiser et se modérer au point de vue social (dans l'Ouest les protestants sont très massivement des paysans). Dans le Sud-Est, il est clair que le peuple protestant hésite ; dans cette région les souvenirs de la Terreur blanche sont encore vifs et, surtout, assez souvent les bonapartistes ne sont pas assez forts pour se battre seuls et ils ont besoin de l'appui des royalistes, que les protestants regardent comme leurs ennemis. Mais l'image de Bonaparte n'est pas encore claire et ses intentions assez confuses; d'où la variété des réponses protestantes. Toutefois dès 1848 les régions protestantes du Sud-est ne semblent pas destinées à devenir une terre d'élection pour le bonapartisme.

Le coup d'État du 2 décembre 1851, et les soulèvements républicains des jours suivants, permettent de confirmer cette première analyse ${ }^{48}$. Certes la censure ne permet pas à l'opposition de s'exprimer; mais dans un premier temps une fraction de la bourgeoisie protestante imite l'ensemble de la bourgeoisie française et, après avoir été réticente devant le coup d'État, elle se laisse berner dans les jours suivants par la propagande officielle qui décrit les soulèvement républicains, essentiellement légalistes, comme une vaste tentative de jacquerie menaçant l'ordre social. L'attitude du pasteur Athanase Coquerel en fournit un exemple : élu député en 1848 et 1849, il se montre un républicain fort conservateur au point de vue social. Il reste que le 2 décembre, il fait partie de groupe des députés encore libres qui se réunissent à la mairie $\mathrm{du} \mathrm{X}^{\mathrm{e}}$ arrondissement, et il vote la déchéance de Bonaparte, ce qui lui vaut d'être un moment arrêté, comme les autres députés. Mais, dans les jours suivants il s'effraie du tableau que la presse bonapartiste fait de la situation en province, il se rallie et le fait savoir dans le journal qu'il dirige, Le Lien ${ }^{49}$. De la même façon, on peut noter des réactions d'adhésion implicite au nouveau régime dans les deux autres journaux protestants parisiens, L'Espérance et les Archives $d u$ christianisme, rédigés par des membres de la bourgeoisie protestante parisienne ${ }^{50}$. Certes la censure aurait interdit la publication de textes hostiles au nouveau pouvoir, mais ces journaux auraient $\mathrm{pu}$ se retrancher derrière leur caractère religieux pour ne pas exprimer d'opinion politique. Remarquons, aussi, que le Directoire luthérien de Strasbourg fait acte d'adhésion "aux grandes mesures d'ordre public prises par le Président de la République dans l'intérêt de la France ${ }^{51}$. Un certain nombre de consistoires réformés font de même. Le nombre exact n'est pas connu ${ }^{52}$, mais il est clair que moins d'un tiers d'entre eux ont adhéré au coup d'État, ce qui, dans le climat de l'époque ne peut pas être considéré comme un succès pour le pouvoir bonapartiste. On peut donc penser que la plupart des protestants (et donc des consistoires) se trouvant en province et souvent dans de petites villes ou à la campagne, leurs membres ont été à même de mesurer le caractère mensonger de la propagande officielle. Il reste qu'une fraction de la bourgeoisie protestante a partagé la "grande peur» de la bourgeoisie française en décembre 1851. Mais, à nouveau cela ne signifie pas une adhésion à un quelconque bonapartisme idéologique; cela traduit seulement sa volonté de voir un pouvoir fort et qui se réclame, par ailleurs, des principes de 1789 (il ne devrait donc pas être menaçant pour la liberté religieuse des minoritaires), triompher du spectre rouge.

L'étude des réactions du peuple protestant au moment du coup d'État confirme le tableau esquissé en décembre 1848. Dans l'Ouest et le Sud-Ouest, qui n'est guère troublé il est 
vrai, les protestants ne s'insurgent pas et votent très généralement oui lors du plébiscite. Ils persistent donc à regarder le pouvoir bonapartiste comme protecteur et émancipateur. Dans le Sud-Est, en revanche, les protestants sont beaucoup plus sensibles à la nouvelle union du trône et de l'autel qui se concrétise alors et ils craignent pour leur liberté, voire pour leur vie. De plus, les républicains y sont beaucoup mieux organisés et, surtout, la propagande républicaine a porté ses fruits et a convaincu bien des paysans que la République était le meilleur des régimes ${ }^{53}$. De ce fait, dans l'Ardèche, la Drôme et le Gard, les protestants ne sont certes pas les seuls à participer aux soulèvements immortalisés par Zola dans La Fortune des Rougon, mais ils sont nombreux à le faire; même si, naturellement, tous les protestants ne se soulèvent pas dans ces départements. Un pasteur de Nîmes a bien expliqué cette réaction protestante, dans une lettre privée : «Les agents des sociétés secrètes [...] parcoururent les villages et les hameaux ; ils disaient : « Venez défendre la République [...] ». Ils ajoutaient dans les pays protestants : « Vos frères courent des dangers; on veut renouveler les pillages et les meurtres de $1815 »$. Les masses protestantes donnèrent dans le piège et prirent les armes. [...] On prétend que notre peuple est communiste et, en général, il se distingue par plus d'aisance et d'industrie [...] Notre peuple est antilégitimiste. "Plutôt Brama qu'Henri V » me disait un exprésident de club ${ }^{54}$. Certes, les régions où les protestants prennent les armes ne sont pas celles des «forteresses" protestantes des Cévennes - où l'immense majorité des habitants étant protestants, on n'a pas craint le retour de la Terreur blanche, puisqu'on avait les moyens de se défendre - mais plutôt les régions mixtes. Il reste que les résultats du plébiscite corroborent cette analyse : dans le Gard, où les protestants rassemblent $33 \%$ de la population, on dénombre $21 \%$ de «non » alors que la moyenne nationale n'est que de $8 \%$; par ailleurs, le seul canton rural à donner une majorité au « non » $60 \%$, celui de Vernoux en Ardèche, compte $60 \%$ de protestants. En fait, là où ils se sentent menacés par le nouveau pouvoir bonapartiste allié aux royalistes et à l'Église romaine, les protestants sont en grande majorité des opposants. Dans les « forteresses » des Cévennes ils ne jugent pas indispensable de s'opposer au Prince-Président et à ses alliés. Il reste que dans le SudEst de la France, dès 1851, le protestantisme et le bonapartisme ne montrent guère d'affinités.

Durant le Second Empire, ces caractéristiques vont globalement se maintenir. La bourgeoisie protestante n'apprécie guère le régime; d'abord orléaniste, elle glissera, en partie, dans les années 1860 vers un républicanisme modéré et parlementaire. On peut naturellement citer des protestants dans les hautes sphères du régime. Certes, comme entre 1799 et 1815, on ne remarque pas de protestants parmi les proches collaborateurs de l'Empereur ${ }^{55}$, et on note seulement trois protestants nommés ministres par Napoléon III : Achille Fould (ministre des Finances et ministre d'État de façon presque continue de décembre 1851 à janvier 1867), Paul Boudet (ministre de l'Intérieur de juin 1863 à mars 1865) et le maréchal César Randon (ministre de la Guerre de mai 1859 à janvier 1867), tandis que le protestant Georges Haussmann est préfet de la Seine de janvier 1853 à janvier 1870. Au total, sur les 220 préfets nommés sous le Second Empire, on ne compte que huit protestants (soit $3,6 \%{ }^{56}$; c'est certes un peu supérieur à la moyenne nationale des protestants ( $2 \%$ ), mais moins que sous le Premier Empire (où l'on en compte neuf). On peut aussi citer quelques bourgeois protestants connus pour leur attachement au régime, comme Jules Pagézy, grand négociant de Montpellier nommé maire de cette ville en 1852, député de 1863 à 1869 ; le banquier Ernest André, candidat officiel dans le Gard et député de ce département, de 1857 à sa mort en 1864 (il est remplacé par Édouard André, non moins officiel, député de 1864 à 1870) ou le général 
Dautheville, candidat officiel en Ardèche, député de 1854 à $1870{ }^{57}$. Toutefois, il est clair que, dans son ensemble, la bourgeoisie protestante n'est pas bonapartiste ${ }^{58}$. Même un grand négociant bordelais comme Nathaniel Johnston, assez conservateur au point de vue social, n'accepte pas l'étiquette officielle: en 1869 il se présente comme un candidat "dynastique, libéral et indépendant ${ }^{59}$ et une fois élu il adopte une attitude "girondine» (au sens politique du terme), bien éloignée de l'idéologie bonapartiste. Quant à la "banque protestante", restée orléaniste à quelques exceptions près, elle boude ce régime de parvenus, qui n'est pas de son monde, à l'instar de François Guizot, alors l'homme politique protestant le plus connu; il est clair que ce théoricien, et ce praticien, du libéralisme parlementaire ne peut se reconnaître dans le bonapartisme. D'ailleurs, durant les années 1850, on trouve souvent sous la plume des administrateurs locaux l'affirmation selon laquelle la bourgeoisie protestante n'est pas acquise au régime en raison de ses convictions "orléanistes " ou "libérales " ${ }^{60}$. Ainsi, le préfet du HautRhin, évoquant aussi cette forteresse de la bourgeoisie protestante qu'est Mulhouse, écrit : «La communauté protestante ne forme que le dixième de la population du HautRhin [...] mais elle a pour elle la richesse et l'influence qui en est la suite. Son siège principal est à Mulhouse. Jamais elle n'adhèrera franchement et sincèrement au régime impérial. Elle désire le rétablissement de la dynastie déchue [les Orléans] et du régime parlementaire ${ }^{61}$. Commentant le résultat des élections de 1857, le sous-préfet de Castres soutient : « À Mazamet le résultat s'explique facilement. Les protestants y sont nombreux et influents. Or les plus éclairés d'entre eux, soit par tradition soit par intérêt, conservent des tendances républicaines et orléanistes. [...] Quant aux ouvriers protestants, ils sont pour la plupart démagogues " ${ }^{62}$. Un peu plus tard, en 1858, le sous-préfet de Montélimar affirme : «C'est parmi eux [les protestants] que se trouvent spécialement les partisans de idées orléanistes au sujet de la liberté de la presse et du système parlementaire en honneur sous Louis-Philippe ${ }^{63}$. Vers la fin de l'Empire, la situation ne s'améliore pas pour les administrateurs : ainsi, en janvier 1869, le procureur général de Nîmes écrit à propos du département $d u$ Gard: "Une partie de la bourgeoisie protestante [...] transporte du domaine religieux dans celui de la politique ses aspirations libérales et ses doctrines de libre examen [...] [et elle] accueille avec trop de facilité les déclamations de la presse opposante contre les candidatures officielles, contre le retrait des libertés nécessaires et l'exclusion prolongée du système parlementaire ${ }^{64}$. Inutile de multiplier les citations: il est clair que pour la plupart des administrateurs locaux, durant les années 1850 et à la fin des années 1860 , sauf cas particulier ${ }^{65}$ la bourgeoisie protestante ne peut pas être classée parmi les bonapartistes. Et certains expliquent que ce sont leurs options religieuses qui ne leur permettent pas d'accepter les bases idéologiques du régime. D'ailleurs, on remarque aussi des protestants parmi les hommes politiques connus pour leur opposition au régime. Citons, par exemple, le médecin lyonnais Jacques Hénon, l'un des trois députés républicains élus en $1852{ }^{66}$, député de Lyon de 1857 à 1869 , élu maire de Lyon à la chute de l'Empire. Jean-Jules Clamageran familier du salon de Mme Hérold, où il rencontre « la fleur et l'espoir de la République sous l'Empire " ${ }^{67}$ : très actif militant républicain dans les années 1860, il est élu sénateur inamovible en 1882. Ou le pasteur Edmond de Pressensé ${ }^{68}$, connu comme directeur de la Revue chrétienne, mais qui écrit aussi dans d'autres publications, comme la Revue nationale et la Revue des deux mondes et qui fréquente les milieux orléanistes modérés proches des républicains : ami de Benoît Malon, qu'il contribue à sauver pendant la "semaine sanglante », il sera, lui aussi, élu sénateur inamovible en 1883. 

peuple protestant. Certes, celles de 1852 et 1857 sont beaucoup trop contrôlées pour donner des résultats significatifs. De toute façon la politique voyante d'union du trône et de l'autel menée par Napoléon III ne peut que rebuter les protestants, d'autant plus que durant les années 1850, à la demande du clergé catholique, les administrateurs locaux pratiquent souvent une politique de lutte contre l'évangélisation protestante. Cela se traduit, en certains lieux, par le refus de laisser se tenir des cultes protestants dans les communes qui ne possèdent pas de communauté protestante ancienne. Ce qui conduit quelques pasteurs en prison, pour avoir tenu des cultes «illicites» et rappelle, quelque peu, le temps de Louis XIV! Certes le nombre de communes concernées par ces affaires est assez faible, mais cela choque beaucoup les protestants qui regardent la possibilité de célébrer des cultes protestants dans toutes les communes, comme la pierre de touche de leur réintégration dans la communauté nationale (on célèbre des messes catholiques dans toutes les communes). De ce fait, jusqu'à la fin des années 1850, on peut penser qu'en général les communautés protestantes ne sont guère attirées par le régime. cléricaux à partir de 1859. Les élections de 1863 sont donc intéressantes à analyser. De fait les résultats ne permettent pas de retrouver le clivage, décrit en 1848 et 1851, entre un Sud-Est plutôt républicain et un Ouest et Sud-Ouest bonapartiste (anticlérical). Dans le Sud-Est les candidat bonapartistes, en général combattus par les légitimistes et les cléricaux, obtiennent assez fréquemment les voix des protestants; d'autant plus que le pouvoir a souvent l'habileté de présenter des candidats officiels protestants dans les arrondissements où leurs coreligionnaires sont nombreux : un sur quatre dans le Gard (Ernest André), deux sur trois en Ardèche (le général Dautheville et le comte Boissy d'Anglas), deux sur trois dans l'Hérault (Jules Pagézy et Brutus Cazelles), un sur trois dans la Drôme (Théodore Morin). Or comme le parti républicain n'est pas encore reconstitué (il ne parvient pas à présenter un candidat dans toutes les circonscriptions, loin de là) et que les candidats bonapartistes n'apparaissent pas comme les valets des royalistes cléricaux qui avaient encouragé (voire pratiqué) les exactions et les meurtres de 1815, mais sont au contraire combattus par eux, les protestants n'ont pas de raisons de leur refuser leurs voix. Encore plus lorsqu'il s'agit d'un des leurs. Au fond, en 1863 les protestants du SudEst se retrouvent un peu dans la même position que les huguenots de l'Ouest et du SudOuest: ce sont les candidats bonapartistes qui leur apparaissent comme les meilleurs défenseurs des principes de 1789, et donc de leur liberté (religieuse) et de leur égalité (civile). D'ailleurs, en 1863 les protestants peuvent constater, avec satisfaction que le gouvernement remanié par l'Empereur compte trois protestants (Fould, Boudet et Randon) sur douze ministres (soit $25 \%$, pour $2 \%$ de protestants en France) ${ }^{69}$. simples « clients », les protestants seraient-ils devenus des " partisans » de l'Empereur? En réalité, les administrateurs locaux ne s'y trompent pas : dès juin 1866, par exemple, le préfet du Gard écrit que les populations protestantes «appartiennent généralement à l'opinion républicaine ${ }^{70}$; et même dans l'Ouest et le Sud-Ouest, à compter des années 1867-1868, les protestants sont souvent désignés comme basculant plus ou moins dans l'opposition. D'ailleurs, une analyse précise des résultats des élections de $1869^{71}$ permet de confirmer ce jugement, d'autant plus que le climat de liberté dans lequel elles se déroulent permet aux électeurs d'exprimer leur opinion. Dans le Gard et dans l'Ardèche, par exemple, là où le parti républicain est parvenu à se reconstituer au point 
de représenter une véritable force politique, les protestants lui apportent massivement leurs suffrages et seule la présence de candidats officiels protestants parvient à freiner l'ardeur républicaine des huguenots. Au fond, leur ralliement de 1863 n'était que conjoncturel ; dès qu'ils ont été en mesure de trouver mieux, les « clients » protestants de Napoléon III ont changé de "fournisseur». Quant à l'essai d'Empire libéral au début de l'année 1870, il est trop bref pour qu'on puisse tenter de voir si ce nouvel avatar du bonapartisme aurait pu mieux convenir aux huguenots que ne le feront les républicains anticléricaux de la Troisième République, mais c'est peu probable parce qu'alors l'Empire reprend nettement une teinte cléricale.

Les textes anti-bonapartistes que l'on peut lire dans la presse protestante dès le lendemain du 4 septembre 1870 ne sont donc pas une simple expression d'opportunisme. Ils correspondent à l'état de l'opinion protestante à la fin de l'Empire. Le Lien écrit ainsi : « il nous est impossible de cacher ici [...] combien nous avons toujours souhaité la fin du régime étouffant que nous avons subi depuis vingt années ${ }^{72}$. Quant à Edmond de Pressensé, il affirme dans le premier numéro de la Revue chrétienne ${ }^{73}$ paru après la proclamation de la République : « Elle [la guerre] a été le dernier attentat de ce qu'on peut appeler la bande de décembre qui ne voulait pas abandonner le pays alors qu'il commençait à lui échapper. C'est le pouvoir personnel qu'elle voulait repêcher dans le sang et avec le pouvoir personnel la faculté d'exploiter la France à son aise " ${ }^{74}$. D'ailleurs, après 1870 la très rapide adhésion à la République du peuple protestant et d'une grande partie de ses élites, les pasteurs en particulier, montre bien le faible impact du bonapartisme dans les rangs des protestants.

Peut-on donc déceler une certaine incompatibilité entre le protestantisme français et le bonapartisme? La réponse est difficile, dans la mesure où le bonapartisme est lui-même peu théorique et variable dans le temps. Il reste qu'au XIXe siècle les protestants sont avant tout soucieux de préserver la liberté religieuse et l'égalité civile dont ils ont été privés durant un siècle. De ce fait, la plupart d'entre eux ne sont pas hostiles au Premier Empire, en dépit de son essence autoritaire, parce qu'il a reconnu leurs Églises et affirmé sa volonté de faire respecter l'égalité des cultes. La réticence de bien des huguenots envers Napoléon III vient certes de l'aspect très autoritaire que son régime revêt dans les années 1850 (plutôt contraire aux conclusions politiques que les protestants tirent de la doctrine du sacerdoce universel), mais surtout de l'alliance du trône et de l'autel, évidente dès 1849 (expédition de Rome) et de ses liens avec la fraction la plus conservatrice de la société, que les protestants soupçonnent de nourrir de noirs desseins à leur égard ${ }^{75}$. C'est donc l'anticléricalisme qui guide avant tout les choix politiques des protestants français; mais il s'agit d'un anticléricalisme spécifique, différent de celui que pratiquent après 1879 les républicains agnostiques d'origine catholique ${ }^{76}$. Et si dans l'Ouest les protestants acceptent de voter pour les candidats officiels, c'est aussi parce que, dans ces régions, ceux-ci leur semblent défendre les principes de 1789. Mais tel n'est pas le cas partout ; plus le temps passe et plus les républicains modérés des années 1860 apparaissent aux protestants comme de meilleurs défenseurs, d'autant plus que les principes qui les guident ne sont nullement en contradiction avec le sacerdoce universel, bien au contraire. 


\section{NOTES}

1.. L'Église libre du 9 septembre 1870, p. 281, colonne 2.

2.. Il écrit : « Malheureusement la France, en grande partie, était complice. Un jour cet homme qui, la première fois, lui avait arraché un oui en lui mettant son genou sur la poitrine, lui demanda si elle voulait renouveler son pacte d'alliance, et l'épouser pour de bon. La France, hélas ! avait passé [sic] par dix-neuf ans d'Empire, et elle répondit par sept millions cinq cent mille voix : oui, je t'épouse. [...] Ce jour là, bien certainement, il se passa quelque chose dans les conseils de Dieu. L'orage de sa colère a éclaté, soudain, terrible !... La nation était coupable, la nation entière a été frappée. [...] nous avions péché, et attiré sur notre tête nos malheurs ». (Idem, colonne 3).

3.. Texte cité dans l'Almanach des protestants de l'empire français pour l'an de grâce 1809, par M. A. M. D.- G., Paris, Éditions Gautier et Bretin, 1809, pp. 229-230.

4.. On peut, naturellement, citer des exemples contraires; nous ne nous plaçons ici que sur le plan des principes.

5.. On peut trouver un exemple de ce type de réaction chez Jean-Jacques Rousseau qui, bien qu'il soit citoyen de la République de Genève, a longtemps vécu en France au temps des persécutions. Il écrit notamment dans le Contrat social, paru en 1762 : « il n'y a plus, il ne peut plus y avoir de religion nationale exclusive, on doit tolérer toutes celles qui tolèrent les autres, autant que leurs dogmes n'ont rien de contraire aux devoirs du citoyen. Mais quiconque ose dire Hors de l'Église point de salut, doit être chassé de l'État ; à moins que l'État ne soit l'Église et que le prince ne soit le pontife. [...] La raison sur laquelle on dit qu'Henri IV embrassa la religion romaine la devrait faire quitter à tout honnête homme, et surtout à tout prince qui saurait raisonner "; Jean-Jacques ROUSSEAU, Du contrat social, Paris, Éditions Garnier-Flammarion, 1966, Livre V, p. 180. 6.. Ainsi, par exemple, dans l'Encyclique Libertas (1888), le pape Léon XIII rappelle l'hostilité de l'Église romaine à la liberté religieuse.

7.. On peut remarquer qu'aujourd'hui on compte quatre monarchies protestantes (Grande-Bretagne, Hollande, Danemark et Suède), trois musulmanes (Maroc, Jordanie, Arabie saoudite), deux catholiques (Espagne et Belgique), une bouddhiste (Cambodge) et une shintoïste (Japon).

8.. Pour plus de détails consulter Frédéric BLUCHE, Le bonapartisme aux origines de la droite autoritaire (1800-1850), Paris, Nouvelles Éditions Latines, 1980 et Le bonapartisme, «Que saisje ? ", Paris, Presses Universitaires de France, 1981, 128 p.

9.. Jacques-Olivier BOUDON, Le Consulat et l'Empire, Paris, Éditions Montchrestien, 1997, p. 8.

10.. René RÉMOND, La vie politique en France. Tome 2 : 1848-1879, Paris, Éditions Armand Colin, 1969, p. 155.

11.. Consulter, notamment, à ce propos l'ouvrage de Bernard MÉNAGER, Les Napoléon du peuple, Paris, Éditions Aubier, 1988, 445 p.

12.. Dans cet article nous analyserons, pour l'essentiel, les choix des protestants réformés ; certes l'attitude des luthériens est non moins intéressante mais ceux-ci, installés pour l'essentiel en Alsace, n'ont pas connu le régime de l'Édit de Nantes et sa révocation n'a pas eu les mêmes conséquences que pour les réformés « de l'intérieur ». Les protestants 
alsaciens sont vivement tracassés par Louis XIV et ses successeurs, mais ils ne sont pas persécutés, au sens strict ; et par exemple, ils conservent en général la liberté de culte. De ce fait, leurs réactions ne sont pas identiques à celles des réformés.

13.. Les protestants représentent donc $20 \%$ de ce syndicat de banquiers " bonapartistes ", alors qu'ils ne rassemblent pas plus de $2 \%$ de la population française. Mais il ne faut pas tirer trop de conclusions de ces chiffres, qui montrent surtout qu'en 1799 les milieux du négoce sont heureux de la stabilisation de la situation politique. Voir Louis BERGERON, Banquiers, négociants et manufacturiers parisiens du Directoire à l'Empire, Lille/Paris, Atelier national de reproduction des thèses/Librairie Honoré Champion, 1975, 2 volumes, XXIV-860 p.

14.. Notons, a contrario, que Charles-Frédéric Reinhard, fils d'un pasteur luthérien alsacien, est nommé ministre des relations extérieures par Sieyès le 20 juillet 1799, mais qu'il démissionne après le 18 brumaire ; voir Michel-Edmond RICHARD, Notables protestants en France dans la première moitié du XIX ${ }^{e}$ siècle, Caen, Éditions du Lys, 1996, pp. 24-25. Dans cet ouvrage, Michel-Edmond Richard affirme qu'en dépit d'une légende tenace à ce propos, Crétet, ministre de l'intérieur de 1807 à 1809, n'est pas protestant. 15.. L'Alsace mise à part, tous les établissements d'enseignement français (primaire, secondaire et supérieur) sont alors entre les mains de l'Église catholique et tous les élèves sont réputés catholiques; en France, les protestants ne peuvent donc pas acquérir la formation nécessaire pour être en mesure de servir l'État. C'est l'une des raisons qui explique la part (relativement) importante prise par les protestants dans le monde des affaires à la fin du XVIII ${ }^{e}$ siècle : alors on se forme surtout par " apprentissage » et les fils de négociants protestants peuvent se perfectionner à l'étranger auprès de coreligionnaires en relation d'affaires avec leur père (quand il ne s'agit pas de membres de leur famille ayant fui la France après 1685).

16.. Remarquons que Charles-Frédéric Reinhard, cité note 14, est alsacien et qu'il a pu faire des études supérieures à Strasbourg. Quant à Necker, il s'est naturellement formé en Suisse, sans aucune difficulté.

17.. « À des interlocuteurs protestants, il [Bonaparte] tint - premier consul - des propos aimables auxquels il ne faut probablement pas attacher plus d'importance que de courtoises mondanités [...] » écrit Daniel ROBERT dans Les Églises réformées en France, 1800-1830, Paris, Presses Universitaires de France, 1961, p. 49.

18.. Ces chiffres, ainsi que les suivants, sont extraits du livre de Michel-Edmond RICHARD, Notables protestants..., ouv. cité, passim.

19.. Pour les deux autres, l'un est d'origine suisse (Perregaux) et l'autre (Rigal) est né en Allemagne mais il est issu d'une famille huguenote « réfugiée » au Wurtemberg. En 1810, après l'annexion de la Hollande à l'Empire cinq protestants néerlandais sont nommés sénateurs; nous ne les incluons pas dans nos comptes.

20.. Mais sur les 20 généraux nommés entre 1788 et 1798 une bonne partie a servi aussi sous le Consulat et l'Empire.

21.. La position de Guizot à la Sorbonne semble de prime abord contredire notre affirmation sur la difficulté pour les protestants de se former sur le plan intellectuel. Mais, outre que Guizot est né en 1787 quelques semaines avant la signature de l'Édit de Tolérance, il effectue ses études secondaires à Genève (après l'exécution de son père en 1794, sa mère s'est fixée à Genève) au moment où, en France, la désorganisation de l'enseignement induite par la suppression des ordres religieux rend difficile la formation de tous les jeunes Français. Par ailleurs, Guizot n'a pas étudié dans un établissement d'enseignement supérieur ; et il est très jeune ( 25 ans) lorsqu'il est nommé à la Sorbonne. 
22.. Cité par Michel-Edmond RICHARD, Notables protestant..., ouv. cité, p. 15.

23.. Cité, notamment, par Paul BASTID, Benjamin Constant et sa doctrine, Paris, Éditions Armand Colin, 1966, volume 1, p. 280.

24.. Ce qui permet à Chateaubriand d'écrire à ce propos : « Dieu nous garde de triompher des misères dont les natures les plus élevées ne sont point exemptes! Le ciel ne nous donne des talents qu'en y attachant des infirmités ; expiation offerte à la sottise et à l'envie »; François-René de CHATEAUBRIAND, Mémoires d'outre-tombe, Édition du centenaire, Paris, Éditions Flammarion, 1948, volume 3, p. 385.

25.. En le chargeant de mettre au point la constitution Napoléon lui dit, notamment : « [... ] des discussions publiques, des élections libres, des ministres responsables, la liberté de la presse [...]. Je veux tout cela [...] »; cité par Jacques GODECHOT, Les constitutions de la France depuis 1789, Paris, Éditions Garnier-Flammarion, 1970, p. 227.

26.. Notons qu'il considère la liberté religieuse comme la première de toutes les libertés.

27.. Cité, notamment, par Paul BASTID, Benjamin Constant..., ouv. cité, volume 2, p. 729.

28.. Benjamin Constant est né à Lausanne en 1767 mais par son père, originaire de l'Artois et par sa mère (famille Chandieu) du Dauphiné, il est issu de familles du « refuge ».

29.. Cité par Michel-Edmond RICHARD, Notables protestants..., ouv. cité, p. 16.

30.. François GUIZOT, Mémoires pour servir à l'histoire de mon temps, Paris, Éditions Michel Lévy, 1858, volume 1, pp. 4-5.

31.. Almanach des protestants pour 1810, rédigé et mis en ordre par M. A. M. D.-G., deuxième partie, Paris, Librairie protestante, 1810, p. 51. Ce recueil contient un certain nombre d'adresses de ce type. Voir aussi l'article de Félix KUHN, dans Bulletin de la Société de l'histoire du protestantisme français, 1900, pp. 320-326 et 375-387.

32.. Rabaut-Dupui, l'un des protestants consultés par le pouvoir à propos de la mise au point des Articles organiques, écrit par exemple le 15 avril 1802 au pasteur OlivierDesmont, de Nîmes : « il serait important que les protestants adressassent au Premier Consul, de plusieurs points, des adresses de remerciements, courtes et bonnes qui fissent honneur [...] »; cité par le Comte BOULAY de la MEURTHE, Documents sur la négociation du Concordat, Paris, Éditions Leroux, 1891-1897, volume 5, p. 429.

33.. Voir Daniel ROBERT, Les Églises réformées..., ouv. cité, pp. 47-107.

34.. RABAUT LE JEUNE, Annuaire ou répertoire ecclésiastique à l'usage des Églises réformées et protestantes de l'Empire français, Paris, chez M. le pasteur Rabaut-Pomier, 1807, pp. 5-6.

35.. Daniel ROBERT, Les Églises réformées..., ouv. cité, p. 259.

36.. On pourrait objecter que les Bourbons avaient fait tuer beaucoup plus de protestants avant 1789 ; certes, mais sous l'Ancien Régime les protestants ne remettaient pas en cause la légitimité du roi, ils espéraient le retour à un régime proche de l'Édit de Nantes. De plus, ils sont particulièrement surpris en 1815 parce qu'ils pensent que la rupture révolutionnaire est telle que la liberté religieuse ne peut plus être mise en question. Or voilà que la présence d'un Bourbon sur le trône provoque meurtres et incendies de temples!

37.. Il déclare, par exemple, pendant la campagne électorale : « Je mettrai mon honneur à laisser au bout de quatre ans à mon successeur le pouvoir affermi, la liberté intacte »; cité par Louis GIRARD, Napoléon III, Paris, Librairie Arthème Fayard, 1986, p. 93.

38.. Maurice AGULHON, 1848 ou l'apprentissage de la république, Paris, Éditions du Seuil, 1973, p. 85.

39.. Le Semeur s'oppose à Bonaparte dès ses premières candidatures (voir, par exemple, le numéro du 14 juin 1848). Le $1^{\mathrm{er}}$ novembre 1848 on peut y lire : « Cette méchante caricature de chef de parti, comme disait autrefois La Presse qui le soutient aujourd'hui, ce jeune homme 
qui n'a pas plus d'esprit que de cœur, comme elle disait encore. Voilà l'homme que l'on propose sérieusement de placer à la tête de l'État ». (p. 337, colonne 1.) Les attaques se poursuivent dans les numéro suivant du Semeur. Un petit hebdomadaire protestant de province (il paraît à Marennes) intitulé Le Catholique apostolique et non romain, soutient nettement la candidature de Cavaignac ; il est vrai que son rédacteur, le pasteur Cambon, sera candidat républicain aux élections législatives de 1849.

40.. Notre analyse des réactions du peuple protestant se limite aux protestants réformés ; en effet l'attitude électorale des luthériens n'a pas fait l'objet de travaux approfondis pour la période 1848-1870.

41.. Les résultats ne sont pas comptabilisés par communes mais par groupes de communes appelés « sections ».

42.. Par exemple : 72,4 \% des voix pour Bonaparte dans le canton d'Anduze (protestant à $83 \%$ ) et $36,7 \%$ dans celui de Vézénobre (73,5\% de protestants). Pour l'analyse complète de l'attitude électorale des protestants réformés, consulter André ENCREVÉ, Protestants français au milieu du XIX siècle, les Réformés de 1848 à 1870, Genève, Éditions Labor et Fides, 1986, pp. 367-504 et 909-976. L'ensemble des chiffres cités dans cet article sont extraits de cet ouvrage.

43.. Consulter Bernard MÉNAGER, Les Napoléon..., ouv. cité ; il écrit notamment : « Plus que les moyens d'expression écrite, la propagande bonapartiste a utilisé les modes d'expression de la culture populaire, permettant la fusion du bonapartisme et du culte napoléonien » (p. 102).

44.. Dans le canton de Vernoux, dont $60 \%$ des habitants sont protestants, Bonaparte ne rassemble que $21,7 \%$ des voix ; mais dans celui de Saint-Agrève, la présence de $46 \%$ de protestants n'empêche pas Bonaparte d'obtenir 72,3\% des voix. Consulter Élie REYNIER, La Seconde République dans l'Ardèche, 1848-1852, Privas, Imprimerie de L. Volle, 1948 et Michel RIOU, «L'élection présidentielle de décembre 1848 en Ardèche », dans Revue du Vivarais, 1974, pp. 82-96.

45.. Consulter Philippe VIGIER, La Seconde République dans la région alpine. Étude politique et sociale, Paris, Presses universitaires de France, 1963, 2 volumes, 328 p et $534 \mathrm{p}$.

46.. Remarquons, toutefois, que dès 1848 dans quelques cantons protestants un fort attachement à la République se manifeste déjà. Tel est le cas dans ceux de Vabre (Tarn), de Vernoux (Ardèche) ou de Bourdeaux (Drôme), par exemple.

47.. Sur ce sujet consulter André ENCREVÉ, Protestants français..., ouv. cité, passim.

48.. Consulter à ce sujet André ENCREVÉ, « Religion et politique au milieu du XIX ${ }^{e}$ siècle, les protestants en décembre 1851 ", dans Christianisme et pouvoirs politiques. Volume 2 : de Napoléon à Adenauer, Lille/Paris, Université Lille 3/Éditions universitaires, 1974, pp. 39-94. 49.. Voir le numéro du 3 janvier 1852, p. 421, colonne 2.

50.. Notons que Le Semeur, hostile à Bonaparte en 1848, a cessé de paraître à la fin de l'année 1850.

51.. Cité par les Archives du christianisme du 12 janvier 1852, p. 7, colonne 1.

52.. Il y a alors 93 consistoires réformés ; Le Moniteur du14 février 1852 affirme que 31 ont adhéré au coup d'État, mais ce chiffre est inexact parce qu'il additionne les véritables adhésions et les simples accusés de réception à la circulaire ministérielle du 29 décembre 1851 qui demande aux consistoires de faire célébrer un service d'actions de grâces le $1^{\mathrm{er}}$ janvier 1852, ce qui est très différent. Je ne suis pas parvenu à déterminer le chiffre exact. 53.. Consulter, à ce sujet, la thèse déjà citée de Philippe Vigier.

54.. Archives nationales (Arch. nat.), $\mathrm{F}^{19} 10$ 186, lettre du pasteur Gardes à l'amiral Baudin, du 6 février 1852. 
55.. Cependant Achille Fould, que Bonaparte nomme ministre des Finances en octobre 1849 et qui devient peu à peu son familier au point de participer directement à la préparation du coup d'État, peut être regardé comme un proche du chef de l'État. D'origine juive il s'est converti au protestantisme sous la monarchie de Juillet. En 1867 ses obsèques seront célébrées dans le temple de l'Oratoire devant un parterre de dignitaires du régime.

56.. Consulter Bernard LE CLÈRE et Vincent WRIGHT, Les préfets du Second Empire, Paris, Presses de la fondation nationale des sciences politiques, 1973, $411 \mathrm{p}$.

57. Sa qualité de militaire a pu jouer un rôle dans son choix bonapartiste.

58.. On ne possède pas d'étude systématique de la confession religieuse des députés élus entre 1852 et 1870 ; il ne m'est donc pas possible de citer des chiffres précis.

59.. Cité par Séverine PACTEAU de LUZE, Les protestants et Bordeaux, Bordeaux, Éditions Mollat, 1999, p. 172.

60.. Ces deux termes sont pratiquement synonymes pour les préfets de ce temps.

61.. Archives départementales du Haut-Rhin, 1 M 62, rapport du 19 décembre 1853.

62.. Arch. nat., $\mathrm{F}^{1} \mathrm{C}^{\mathrm{III}}$ Tarn 7, rapport du 5 juillet 1857.

63. Arch. nat., $\mathrm{F}^{1} \mathrm{C}^{\mathrm{III}}$ Drôme 8 , rapport du troisième trimestre 1858.

64.. Arch. nat., $\mathrm{BB}^{30}$ 389, rapport du 18 janvier 1869.

65.. À Lyon, par exemple, il semble bien qu'une partie au moins de la bourgeoisie protestante se montre acquise au régime, à commencer par Thierry Brölemann, président $\mathrm{du}$ conseil municipal. Consulter Catherine PELLISSIER, « Les notables protestants lyonnais au XIX ${ }^{\mathrm{e}}$ siècle », dans Bulletin de la Société de l'histoire du protestantisme français, 1994, pp. 379-407. « À Lyon, explique Catherine Pellissier, le pluralisme politique des élites protestantes ressort très nettement. [...] Au-delà de la diversité des étiquettes, le libéralisme est valorisé par la bourgeoisie protestante ». (p. 397). En fait, c'est surtout dans les régions où les protestants rassemblent un pourcentage non négligeable de la population que les administrateurs locaux signalent le refus d'adhésion au régime de la bourgeoisie protestante.

66.. On sait que, refusant le serment, les républicains élus en 1852 ne siègent pas.

67.. Louis GIRARD, « Jean-Jules Clamageran » dans André ENCREVÉ et Michel RICHARD [dir.], Les protestants dans les débuts de la Troisième République, 1871-1885. Actes du colloque organisé à Paris du 3 au 6 octobre 1978, Paris, Société de l'histoire du protestantisme français, 1979, p. 176.

68.. Consulter Henri CORDEY, Edmond de Pressensé et son temps, Lausanne, Éditions Bridel, $1916, \mathrm{X}-600 \mathrm{p}$.

69. Chacun sait qu'en 1879 , dans le premier gouvernement constitué après que les républicains ont pris le contrôle de l'ensemble des organes du pouvoir, la moitié des ministres sont protestants ; mais $25 \%$ est déjà un score honorable !.

70.. Rapport du 4 juin 1866, Arch. nat., F ${ }^{1}$ C III Gard 7.

71.. Consulter, à se sujet, André ENCREVÉ, Protestants français..., ouv. cité, pp. 951-976.

72.. Le Lien du 10 septembre 1870, p. 289, colonne 2 (éditorial non signé). Ce journal est dirigé par le pasteur Athanase Coquerel fils.

73.. Déjà dans le numéro d'août 1870 il n'avait pas caché, à mots couverts, son opposition à la guerre.

74.. Revue chrétienne, octobre 1870, p. 514 (la numérotation de ce volume est erronée : après la page 576 la numérotation repart à 513).

75.. Sur l'aspect antiprotestant des milieux traditionalistes, consulter Michèle SACQUIN, Entre Bossuet et Maurras, l'antiprotestantisme en France, Paris, Éditions de l'École des Chartes, 
1998, 526 p. ; et Éric MENSION-RIGAU, Le donjon et le clocher. Nobles et curés de campagne de 1850 à nos jours, Paris, Éditions Perrin, 2003, 508 p.

76.. Sur ces différences, consulter André ENCREVÉ, « Les protestants réformés face à la laïcisation de l'école au début des années 1880 », dans Revue d'histoire de l'Église de France, 1998, pp. 71-96.

\section{RÉSUMÉS}

D'essence autoritaire, le bonapartisme a peu de chance de convenir à ces adeptes du sacerdoce universel que sont les protestants. Toutefois le bonapartisme est issu de la Révolution, il se réclame des principes de 1789, qui ont permis aux protestants de retrouver la liberté et l'égalité, et Bonaparte a donné un statut officiel à leurs Églises. D'où l'attitude complexe, ambiguë des protestants en face du pouvoir bonapartiste. Cependant le cléricalisme dont fait longtemps preuve Napoléon III dans la plus grande partie de la France ne peut convenir aux huguenots, qui, dans la seconde moitié des années 1860 se reconnaissent bien davantage dans le républicanisme modéré.

French Protestantism and Bonapartism. Bonapartism was a form of political authoritarianism. It was therefore very unlikely that Bonapartism could suit the French Protestants, who had always favoured a liberal vision of the Christian religion against that of the Roman Catholic Church. Nevertheless, Bonapartism was also a child of the French Revolution, a child of the political principles of 1789.These principles had allowed the French Protestants to gain Freedom and Equality, and Bonaparte was the one who had given an official status to their Churches, in the early 19th century. For these reasons, the French Protestants established a complex and ambiguous attitude towards Bonapartist power. But the fact that Napoleon III took long-standing positions in favour of the Roman Catholic political ideology couldn't suit them. Therefore, starting from mid-1860's, the French Protestants increasingly became supporters of the moderate republicans.

\section{AUTEUR}

\section{ANDRE ENCREVÉ}

professeur à l'Université Paris 12 